AUTOR

Pablo del Barco*

pablo@

factoriadelbarco.com

* Profesor retirado de

Literatura Española de la

Universidad de Sevilla,

poeta, traductor y artista

gráfico

\section{Sociedad carioca en los años cincuenta; la mirada de Nelson Rodrigues}

\author{
Sociedade carioca nos anos cinquenta; o olhar de Nelson Rodrigues
}

Carioca Society in the 1950s: The View of Nelson Rodrigues

\author{
RODRIGUES, Nelson \\ No tengo la culpa de que la vida sea como es \\ Días Contados: Barcelona, 2015 \\ Traducción: Pablo del Barco
}

Es fácil adivinar bajo la pluma narrativa de Nelson Rodrigues (1912-1980) a un periodista, lo que no supone una desvalorización de su obra, sentida y consentida bajo esa forma de captación de la realidad y análisis que implica la obra de un observador de la vida diaria, de la existencia común. Leyendo los cuentos que se agrupan en su obra No tengo la culpa de que la vida sea como es, que publica la editorial barcelonesa Días Contados como primer número de la serie Lusitana, me han venido a la memoria, sin saber por qué, algunas cartas que escribió Juan Valera desde la capital brasileña en su etapa de secretario de la Legación española, 1851-1853, de diferente tono, por supuesto, pero con semejante intención de constatar una realidad cocinada con fantasía, con elementos que trascienden lo evidente del comportamiento humano. Valera tenía 27 años y un portugués aprendido en Lisboa en su etapa diplomática. Nelson Rodrigues emplea un lenguaje popular de los protagonistas medios de Río de Janeiro, con abundante jerga, que me ha dado no poco trabajo a la hora de traducir la obra. Y no me quejo; como traductor me gustan estas obras que suponen un reto, caminar, a veces con tropezones, por caminos nada sencillos, aunque de abrumadora emoción final.

Reúne treinta y nueve cuentos firmados con su nombre y dos bajo el pseudónimo de Suzana Flag, autora de la columna "Mi destino es pecar" en el diario de Río O Jornal, que consiguió triplicar su tirada, narrando la historia de Leninha, obligada a casarse con Paulo por deudas de familia. La mujer no se conforma con la situación, quiere huir, pero acaba siendo retenida e inicia una relación con el hermano del marido. Las narraciones del libro que publica Días Contados no tienen esta unidad de obra de mayor calibre pero están unidas por un comportamiento en sintonía, un ambiente y una geografía comunes. La ciudad de Río, la playa de la Tijuca, algunos barrios y poblaciones cercanas componen el paisaje, en el que Nelson Rodrigues no gasta demasiada pólvora descriptiva. 
Más notable que este paisaje es el de los sentimientos de los protagonistas, jóvenes en su mayoría y atacados por la necesidad de establecer relaciones afectivas como forma de asentamiento en la sociedad caleidoscópica de la capital de Brasil. A veces no hay un tono amable en las narraciones, no rehúye la violencia pero tampoco la santifica, tal vez porque la ofrece de una manera simple y natural. Algunas situaciones las resuelve con un personaje en el momento del empujón para acabar bajo un autobús, una caída desde una alta ventana de un protagonista que no era el destinado al efecto, mujeres que con sus artimañas obtiene el resultado justamente opuesto al que buscan, enajenaciones mentales, desenlaces inesperados de quienes actúan con una ética contraria a la norma, o una antiética al uso.

Pero lo mejor de todo es el pulso de las narraciones, fechadas entre 1952 y 1960, la sencillez con que están construidas las historias, el afán de modelar personajes con muy pocos elementos, que caminan hacia unos finales que nos ofrecen una necesidad de reflexión, mientras transitan por el humor, a veces inesperado, la ironía, envueltos en capotazos de una realidad en la que antes no habíamos reparado.

Nelson Rodrígues es más conocido por ser el autor de una obra de teatro, Vestido de novia, estrenada el 28 de diciembre de 1943 en el Teatro Municipal de Río de Janeiro, considerada hoy pieza clave en la renovación del teatro brasileño. Estas narraciones de No tengo la culpa de que la vida sea como es se asientan plenamente en la función literaria más habitual del escritor, la periodística; comenzaron a publicarse en el periódico Última hora, con su habitual punto de partida en la realidad y el condimento de la obsesión ficcionista del autor, que se curtió desde muy joven como contador de historias reales en las empresas periodísticas de su padre, Mario Rodrigues. En 1925, a los 13 años, ya era reportero de crónicas policiales en el Diário da Manhã. Estuvo implicado en numerosas empresas periodísticas; en 1928 escribió su primer artículo; desde 1931 se encargó de las páginas deportivas de O Globo de la poderosa familia Marinho.

Pero es en aquella empresa, desde muy joven como cronista policial, donde está el origen de estas narraciones que se nutren, según las propias palabras del escritor, de los hechos policiacos, que "sean cuales sean, representan el gran manantial poético de cada día. Sea homicidio, cabeza partida, atropello, adulterio, agresión, navajazo, tiro, no importa. La verdad es que, del homicidio al robo de una gallina, la crónica policial tiene sus raíces en las grandes pasiones humanas, en los problemas eternos del hombre. Cuando el reportero investiga la "tragedia en Copacabana" está ante una Ana Karenina. Y, entonces, pregunto: ¿por qué ignorar el aura trágica que marca a la pecadora de la vida real y carioca? ¿Por qué negar el valor dramático de un simple atropello?" 